\title{
STUDENTS' PERSPECTIVES ON THE IMPLEMENTATION OF MUSICAL ACTIVITIES IN PRESCHOOL EDUCATION
}

\author{
LIGITA STRAMKALE \\ University of Latvia, Imantas 7. linija 1, Riga, LV-1083 \\ E-mail address: ligita.stramkale@lu.lv
}

\begin{abstract}
Aim. The aim of the study is to find out students' perspectives on the necessity, readiness and disturbing factors of implementing musical activities in preschool. The theoretical part of the paper describes the particularity of preschool teachers' work, the children's interest in musical activities, and the benefits of implementing musical activities in preschool.

Method. The empirical study involved 168 students ( $N=168$ ), of which 132 students $(\mathrm{N}=132)$ are already working as preschool teachers in parallel with their study at the university. The study identified three questions: why do preschool teachers use musical activities? What factors prevent a preschool teacher from using musical activities? Is there a relationship between the competence of a preschool teacher in the field of music and the implementation of musical activities in preschool? In order to answer the study questions, a questionnaire consisting of twelve statements was created, which had to be assessed on a four-point Likert scale.

Results and conclusion. As a result of the analyses of the data obtained in the study, it was ascertained that preschool teachers use musical activities to make children happy and improve their abilities. The use of musical activities is connected with preschool teacher's willingness to do that. One of the key factors that hinders the implementation of musical activities is an insufficient material base in the preschool. The study also found that there is a correlation between the competence of a preschool teacher in the field of music and the implementation of musical activities.
\end{abstract}

Key words: students, preschool teacher, preschool education, musical activities.

\section{INTRODUCTION}

The first-year students of the study program Preschool Teacher should acquire the study course Music Education Methodology in Preschool. During this course, the students are expected to be able to demonstrate knowledge and understanding the musical activities used in preschool education. It is important that students learn how to use their knowledge while they are working as preschool teachers. Why is it important? It is important because the acquisition of music does not end with music lessons in preschool. The particularity of 
preschool work involves several organisation forms, in which musical activities such as singing songs, listening to music, playing musical instruments and doing rhythm exercises are an integral part of them. For example, the preschool teacher with his or her children can get involved in different events, where they should be able to sing songs and play sound tools or musical instruments. Listening to music is integrated into different classroom activities like observing natural events, drawing or learning literary works. Language acquisition is supplemented with rhythm exercises.

Music is one of the means of expression and communication among the members of a society. Many researchers in their studies talk about the positive effects of musical activities on the development of preschool children. It is believed that movement accompanied by music ensures the child's motor and musical development, as well as promoting imagination and friendship (Králova \& Kołodziejski, 2016). The implementation of different types of musical activities in the organization forms of preschool education should develop the children's emotional, creative and evaluative skills. It is also possible to develop participatory skills through implementing the musical activities in the classrooms. Purēns (2017) believes that participation involves creating a positive environment around you, showing initiative to start up, and engaging in joint activity. Joint music making among young children provides the opportunity for the preschool teacher and for the child to understand that it is possible to create an environment around them where everyone feels comfortable and motivated to contribute. This is one way of promoting a child's interest in musical activities.

Several studies have been carried out in music education, which identified the interest of preschool-age children in musical activities. A study conducted by Nita Temmerman (2000) revealed that preschool-age children are wellintentioned to engage in all types of musical activities offered by teachers; however, they prefer to give them musical activities based on movement and playing elements. But another study by Denac (2008) identified and compared the types of musical activities that children aged 5-6 prefer to do in their preschool classrooms and with their family, as well as determined the factors influencing the interest of the children. It was found that the children's favourite musical activities in the classroom are movements accompanied by music, singing songs, and playing instruments, but in their family tradition, listening to music and singing songs are dominant. The researcher believes that the development of children's interest in music depends on teachers' expression of interest in music activities, but in the family the child's interest is developed by the appropriate environment (Denac, 2008). Researchers from Hong Kong and Australia found that children between the ages of 4 and 5 prefer to perform musical activities such as dancing/moving. But some types of musical activities such as singing songs, listening to music and playing musical instruments are connected with the children's cultural contexts (Yim and Ebbeck, 2009). Also, Wassrin (2016) relates musical activities in preschool with a certain culture and social awareness about children, music and knowledge. It is of the utmost importance to take into 
account the studies that have been carried out to determine whether preschool teachers have an interest in implementing musical activities in their classroom. A study conducted by Stolić (2015) determines which musical activities preschool teachers prefer to use in order to develop the children's musical abilities. The researcher has mentioned that preschool teachers consider musical games as one of the most effective musical activities for developing children's musical abilities. However, in this study, as a great surprise, it is found that musical games were ranked fourth of the five types of musical activities. It is determined by the fact that preschool teachers prefer to use singing songs, listening to music and performing counting rhymes.

Preschool children learn from an adult's experience. If the preschool teacher himself is fascinated by some certain types of musical activities, then he may be more interested in encouraging the children to participate in these activities. The aim of the study is to find out the students' perspectives on the necessity, readiness and disturbing factors of implementing the musical activities in preschool.

\section{METHOD}

The study involved 168 first-year students $(\mathrm{N}=168)$, who study in the study program Preschool teacher. 132 students in parallel with their study at the university work as preschool teachers, 36 students do not work. The study took place between February 2017 and December 2017.

The following research questions will be answered in the study:

- Why do preschool teachers use musical activities?

- What factors prevent a preschool teacher from using musical activities?

- Is there a relationship between the competence of a preschool teacher in the field of music and the implementation of musical activities in preschool?

To answer the above-mentioned study questions, a questionnaire consisting of twelve statements was created, which in turn reflected three study dimensions. The first dimension is the students' competence in implementing musical activities during their work. The second dimension is the students' willingness to use musical activities. The third dimension is the factors preventing a preschool teacher from effective implementation of musical activities in the classroom. Each statement of the questionnaire should be assessed by the respondents on a four-point Likert scale. For data processing, the answer variants were transcoded as follows: 4 - yes, 3 - rather yes, 2 - rather no, 1 - no. Each study dimension was considered as inadequate if the arithmetic mean is below 1, the optimal level ranging from 1.01 to 2.00 , an adequate level ranging from 2.01 to 3.00, and a high level ranging from 3.01 to 4 .

The Statistical Package for Social Science (SPSS Statistics 22) was used to analyse the questionnaire results. The internal consistency and security of the study dimensions are determined by Cronbach's Alpha coefficient. The main 
(M), standard deviation (SD), and standard deviation error (SE) are calculated for each statement. In order to determine if there is a relationship between the preschool teacher's competence in the field of music and the implementation of musical activities in preschool, a bivariate (Pearson) correlation is calculated. The sample correlation coefficient has statistically significant values ranging from 0.01 to 0.05 .

\section{RESEARCH RESULTS}

The internal consistency for all three study dimensions is high enough $(a=.786)$. This will make it possible to analyse the data obtained for each study dimension, and to answer the questions raised by the study.

The first study dimension is to determine the students' competence in the implementation of musical activities. This competence will be acquired as a result of student's learning process over a long period of time. The study course "Music Education Methodology in Preschool" should provide the opportunity for the students as future preschool teachers in their first academic year with the needed professional competence, in order to ensure an effective implementation of musical activities in preschool education.

Table 1. The competence in implementing musical activities

\begin{tabular}{l|c|c|c}
\hline \multicolumn{1}{c}{ Statement } & M & SD & SE \\
\hline I have ideas on how to use musical activities & 3.1905 & .66724 & .07280 \\
\hline I know how to use musical activities & 2.7500 & .69204 & .07551 \\
\hline Using musical activities is not a problem for me & 2.8452 & .78378 & .8552 \\
\hline $\begin{array}{l}\text { I cannot use musical activities because there is } \\
\text { not enough competence }\end{array}$ & 2.9643 & .82792 & .09033 \\
\hline
\end{tabular}

Source: author

Table 1 shows the students' self-assessment of their competence in implementing musical activities. The statement I have ideas on how to use musical activities has a high self-assessment of students. The study found that there is a correlation between the students' competence in using different types of musical activities and the existence of ideas about the use of musical activities $(r=0.318$; $\mathrm{p}<0.01$ ). The students have ideas for using musical activities if that does not cause any difficulties for them $(\mathrm{r}=0.310 ; \mathrm{p}<0.01)$, and if sufficient material base is provided $(\mathrm{r}=0.282 ; \mathrm{p}<0.01)$. The students believe that their level of knowledge about the use of musical activities is optimal. The knowledge of an effective implementation of musical activities in the classroom provides the students with a sense of confidence $(r=0.316 ; p<0.01)$, helps them to achieve the goal $(r=0.237$; $\mathrm{p}<0.05)$ and creates new ideas $(\mathrm{r}=0.313 ; \mathrm{p}<0.01)$. The information about the types of musical activities that is acquired during the study process enables the students' to include music listening, the technique of developing a sense of rhythm, singing and musical games in their preschool classroom $(r=0.322 ; p<0.01)$. 
The second study dimension determines the students' willingness to use musical activities. The students recognised the multiple benefits of implementing musical activities in preschool education. Musical activities provide the preschool teachers with numerous opportunities to achieve learning goals, spread joy among children, improve children's understanding of making music and develop children's abilities (table 2).

Table 2. Why do preschool teachers use musical activities in their work?

\begin{tabular}{l|c|c|c}
\hline \multicolumn{1}{c}{ Statement } & M & SD & SE \\
\hline To achieve goals & 3.1786 & .643005 & .07016 \\
\hline To spread joy among children & 3.7024 & .55493 & .06055 \\
\hline $\begin{array}{l}\text { To improve children's understanding of making } \\
\text { music }\end{array}$ & 3.2738 & .73388 & .08007 \\
\hline To develop children's abilities & 3.3929 & .69452 & .07578 \\
\hline
\end{tabular}

Source: author

The majority of students believe that the use of musical activities makes children happy. Spreading joy and happiness among children will create a positive emotional climate in the classroom. These feelings can have a positive effect on children's behaviour and provide the preschool teacher with the opportunities to achieve the learning goals $(\mathrm{r}=0.353 ; \mathrm{p}<0.01)$. The musical activities, which make children happy, promote understanding the process of making music $(r=0.380 ; p<0.01)$ and develop children's abilities $(r=0.401 ; p<0.01)$.

The preschool teachers need to achieve a certain level of competence in implementing musical activities in order to increase the children's experience and awareness of a certain type of musical activities $(\mathrm{r}=0.305 ; \mathrm{p}<0.01)$. The preschool teacher should understand the methods of implementing musical activities in preschool education in order to be able to improve children's abilities $(r=0.383 ; p<0.01)$.

The third study dimension is to identify the disturbing factors facing a preschool teacher in implementing musical activities. The students believe that the sense of confidence, planning of time, insufficient material base and the willingness to do are the main factors that prevent preschool teachers from using musical activities (table 3).

Table 3. The disturbing factors of using musical activities

\begin{tabular}{l|c|c|c}
\multicolumn{1}{c}{ Statement } & M & SD & SE \\
\hline Sense of confidence & 3.1429 & .66119 & .07214 \\
\hline Planning of time & 3.2976 & .74088 & .08084 \\
\hline Material base & 3.0357 & .92419 & .10084 \\
\hline Willingness to do & 3.4405 & .71728 & .07826 \\
\hline
\end{tabular}

Source: author

The materials and equipment in preschool classrooms are very important for the students, especially if there is a lack of ideas on how to use musical 
activities $(r=0.282 ; p<0.01)$ and if a certain level of competence in implementing musical activities is not achieved $(\mathrm{r}=0.443 ; \mathrm{p}<0.01)$. In this case, the learning materials that have been already prepared and the appropriate material base should facilitate the planning of time for musical activities $(\mathrm{r}=0.477 ; \mathrm{p}<0.01)$. The limited resource as a disturbing factor is also mentioned in the study conducted by Rajan (2017).

From the four statements shown in table 3, the students are more likely to agree on the statement Willingness to do. The students' willingness to include musical activities in the classroom is closely connected with their sense of confidence $(r=0.552 ; p<0.01)$, knowledge and skills $(r=0.322 ; p<0.01)$. The fewer students face difficulties in implementing musical activities, the more they want to use them in their classrooms $(r=0.337 ; \mathrm{p}<0.01)$. The students' willingness to use musical activities is more related to the orientation towards the child rather than the content of a certain lesson. The students prefer to use musical activities in the classroom if this will spread joy and happiness among children $(r=0.364 ; p<0.01)$ and improve the children's abilities $(r=0.383 ; p<0.01)$.

If the lack of time is considered to be a disturbing factor in implementing musical activities, then the most likely problem is the planning of time. The students have difficulties in musical activities' time planning, if they have not a certain level of competence to implement musical activities in the classroom $(\mathrm{r}=0.489 ; \mathrm{p}<0.01)$, and if there is an insufficient material base in the preschool $(\mathrm{r}=0.477 ; \mathrm{p}<0.01)$. The study found that the students use musical activities if they are competent enough $(r=0.284 ; p<0.01)$ and feel confident about the outcome $(\mathrm{r}=0.364 ; \mathrm{p}<0.01)$.

\section{CONCLUSIONS AND DISCUSSION}

Nowadays there are several approaches to implement musical activities in preschool education. In Latvia, similar to Estonia (Kiilu, 2011), music education is firmly positioned as a part of preschool education system.

It is important for preschool teachers to have the needed skills and knowledge to implement musical activities in their classrooms in an effective way. Several studies prove the importance of acquiring music during the preparation process of preschool teachers (Ehrlin \& Gustavsson, 2015) and its implementation in their work at the preschool (Kihoro, 2017).

The study found that the majority of preschool teachers use musical activities to spread joy and happiness among children in the classroom $(\mathrm{M}=3.7024$; $\mathrm{SD}=.55493$ ). The preschool teachers, while using musical activities, are also interested in the development of children's abilities ( $\mathrm{M}=3.3929$; $\mathrm{SD}=.69452)$. The researchers have similar thoughts and believe that music needs to be integrated into other preschool activities. The researchers see various benefits of implementing musical activities in the development of the child's general abilities. For example, music and movement together provide many benefits to the 
cognitive, social, emotional and physical development of children (Garrison \&Walls-Advisor, 2013). It promotes the child's healthy development (IzumiTaylor, Morris \& Meredith, Hicks, 2012) and creative thinking (Chronopoulou \& Riga, 2012). Music integrated with information technology promotes the child's perception and creativity (Panagiotakou \& Pange, 2010). The use of music in acquiring a foreign language intensifies the interest in this language (Lee \& Lin, 2015). The researchers have found that preschool teachers through musical activities could develop the child's musical abilities such as a sense of rhythm (Özmentes, 2010).

The research found that preschool teachers connect the implementation of musical activities in the classroom with the willingness to do that $(M=3.4405$; $\mathrm{SD}=.71728$ ). However, the material base and equipment in the classroom are no less important $(\mathrm{M}=3.0357 ; \mathrm{SD}=.92419)$. Researchers from Cyprus have found that preschool teachers want to have a separate music room, musical instruments and other music-related materials (Ekizoglu, Ekizoglu, 2009). There are several options to overcome the limited material resources in preschool. For example, Süner \& Ünlü (2013) recommend hand-made musical instruments, which provide a unique and fun experience for children.

The study determines that there is a correlation between the preschool teachers' competence in the field of music and the implementation of musical activities $(\mathrm{r}=0.284 ; \mathrm{p}<0.01)$. The researchers Ehrlin \& Wallerstedt (2014), while studying the musical abilities of preschool teachers, have found that the teachers work confidently with different types of musical activities and have a good level of competence in this field. However, an interview reveals that teachers doubt their musical abilities, and consider that they cannot sing or play musical instruments. The researchers related this to the fact that the teachers talk about music as a method for teaching language, but they realise it in practice as the content of learning (Ehrlin \& Wallerstedt, 2014). In the further study, it is necessary to identify the causes that affect students' competence to use musical activities in the preschool.

\section{REFERENCES}

1. Chronopoulou, E., \& Riga, V. (2012). The contribution of music and movement activities to creative thinking in pre-school children. Creative Education, 3(2), 196-204.

2. Denac, O. (2008). A case study of preschool children's musical interests at home and at school. Early Childhood Education Journal, 35 (5), 439-444.

3. Ehrlin, A., \& Gustavsson, H.O. (2015). The importance of music in preschool education. Australian Journal of Teacher education, 40(7), 32-42.

4. Ehrlin, A., \& Wallerstedt, C. (2014). Preschool teachers' skills in teaching music: Two steps forward one step back. Early Child Development and Care, 184(12), 1800-1811.

5. Ekizoglu, A., \& Ekizoglu, N. (2009). Musical activities in pre-school institutions (case of Nicosia). Procedia Social and Behavioral Sciences, 1, 302-303.

6. Garrison, B., \& Walls-Advisor, J. (2013). Integrating music and movement into an early childhood education curriculum. Muncie, Indiana: Ball State University. Retrieved from http:/ /cardinalscholar.bsu.edu/bitstream/handle/123456789/197204/GarrisonB_2013-2_BODY.pdf;jsessio nid=6AABD0143C95E68D397D3BCB140EC310?sequence=1 
7. Izumi-Taylor, S., Morris, V.G., Meredith, C.D., \& Hicks, C. (2012). Music and movement for young children's healthy development. Dimensions of Early Childhood, 40(2), 33-39.

8. Kihoro, M. (2017). One, two, sing! How preschool teachers utilize music activities in the classroom: A case of Kiambu County, Kenya. European Journal of Education Studies, 3(12), 490-501.

9. Kiilu, K. (2011). The concept of preschool music education in Estonian education system. Procedia - Social and Behavioral Sciences, 29, 1257 - 1266.

10. Králová, E., \& Kołodziejski, M. (2016). Music and movement activities for preschool children as an incentive to foster relationships and the expression of movement. Elementary Education in Theory \& Practice, 11(3), 185-205.

11. Lee, L., \& Lin, S. (2015). The impact of music activities on foreign language, English learning for young children. Journal of the European Teacher Education Network, 10, 13-23.

12. Özmentes, S. (2010). Pre-school teachers' implications about the rhythm applications in music lessons. Procedia Social and Behavioral Sciences, 9, 255-259.

13. Panagiotakou, C., Pange, J. (2010). The use of ICT in preschool music education. Procedia Social and Behavioral Sciences, 2, 3055-3059.

14. Purēns, V. (2017). Kā attīstìt kompetenci? [How to develop competence?]. Rīga: RaKa.

15. Rajan, R. (2017). Preschool teachers' use of music in the classroom: A survey of park district preschool programs. Journal of Music Teacher Education, 27(1), 89-102.

16. Stolić, J. (2015). Development of preschool children's musical abilities through specific types of musical activities. Research in Pedagogy, 5(2), 31.44.

17. Süner, S., \& Ünlü, C. E. (2013). Musical instruments made by small hands: A multifunctional activity at preschools in Turkey. Procedia - Social and Behavioral Sciences, 93, 1879 - 1884.

18. Temmerman, N. (2000). An investigation of the music activity preferences of pre-school children. British Journal of Music Education, 17(1), 51-60.

19. Wassrin, M. (2016). Rethinking music activities in preschool. Nordic Research in Music Education, 17. 103-136.

20. Yim, H. Y. B., \& Ebbeck, M. (2009). Children's preferences for group musical activities in child care centres: A cross-cultural study. Early Childhood Education Journal, 37(2), 103-111. 